\title{
AVALIAÇÃO DA ATIVIDADE ANTIBACTERIANA E MODULADORA DO ÓLEO ESSENCIAL DE Cordia verbenacea DC. ASSOCIADO ÀS LUZES DE LED
}

\section{EVALUATION OF THE ANTIBACTERIAL AND MODULATOR ACTIVITY OF ESSENTIAL OIL OF Cordia verbenacea DC. ASSOCIATED WITH LED LIGHTS}

MATIAS $^{1}$, Edinardo Fagner Ferreira; BEZERRA ${ }^{\mathrm{a}}$, Viviane Bomfim; BARROS ${ }^{\mathrm{a}}$, Rizelle de Oliveira; LUCENA ${ }^{\mathrm{a}}$, Ana Leticia Vidal Madeiro de; LEITEa, Vanessa Dantas; FEITOSA a , Jessica Horana Fernandes; Maria Karollyna do Nascimento SILVA $^{\mathrm{a}, \mathrm{b}}$;

${ }^{a}$ Centro Universitário Dr. Leão Sampaio - UNILEÃO (Juazeiro do Norte - CE)

b Programa de Pós-Graduação em Bioprospecção Molecular: Universidade Regional do Cariri - URCA (Crato - CE)

Recebido: 20/12/2017; Aceito: 14/03/2018; Publicado: 22/03/2018

\section{RESUMO}

Light Emitting Diodes - LED são diodos emissores de luz, com inúmeras propriedades estéticas e farmacológicas. Cordia verbenacea DC, conhecida como "erva-baleera", é utilizada popularmente no combate a doenças infecciosas e inflamatórias. O presente estudo tem como objetivo avaliar a atividade antibacteriana e moduladora do óleo essencial das folhas de $C$. verbenacea associadas às luzes LED. O óleo essencial das folhas de $C$. verbenacea $(\mathrm{OECv})$ foi obtido pelo método de hidrodestilação. A atividade antibacteriana e moduladora foi realizada através do método de contato gasoso com o uso de OECv, luzes de LED e antibióticos (amicacina, gentamicina, oxacilina, ciprofloxacina, penicilina e norfloxacina). Os testes foram realizados em triplicata e submetidos à análise estatística ANOVA com teste de significância para $p<0,05$. Nos testes de avaliação antibacteriana não foi observado potencial antibacteriano da OECv associada às luzes LED. Na modulação da resistência bacteriana, observou-se que as combinações do OECv + antibiótico + LED apresentaram sinergismo, antagonismo e indiferença frente às linhagens multirresistentes de Staphylococcus aureus e Escherichia coli, apresentando a atividade mais expressiva com o antibiótico penicilina. Os diferentes resultados indicam que a atividade biológica da OECv dependerá da metodologia aplicada, bem como da parte vegetal utilizada, conforme descrito em vários estudos que avaliaram a mesma atividade antibacteriana por diferentes métodos e produtos naturais desta espécie. Os resultados obtidos tornam-se importantes para colaborar com pesquisas futuras para novas metodologias na terapia de infecções causadas por bactérias multirresistentes elucidando os efeitos moduladores obtidos com o uso combinado das luzes LED associadas a óleos essenciais.

Palavras-chave: Cordia verbenacea. Atividade antibacteriana. Fototerapia. Produtos naturais.

\begin{abstract}
Light Emitting Diodes - LED are light emitting diodes, with numerous aesthetic and pharmacological properties. Cordia verbenacea, known as "erva-baleera", is popularly used in the fight against infectious and inflammatory diseases. The present study aims to evaluate the antibacterial and modulatory activity of the essential oil of $C$. verbenacea leaves associated with LED lights. The essential oil of $C$. verbenacea leaves (OECv) was obtained by the hydrodistillation method. The antibacterial and modulating activity was performed through the gaseous contact method with the use of OECv, LED lights and antibiotics (amikacin, gentamicin, oxacillin, ciprofloxacin, penicillin and norfloxacin). The tests were performed in triplicate and submitted to ANOVA statistical analysis with significance test for $p<0.05$. In the antibacterial evaluation tests, no antibacterial potential of the OECv associated with LED lights was observed. In the tests of modulation of bacterial resistance, it was observed that the combinations of $\mathrm{OECv}+$ antibiotic + LED presented synergism, antagonism and indifference to the multiresistant strains of Staphylococcus aureus and Escherichia coli, showing the most expressive activity with the antibiotic penicillin. The different results indicate that the biological activity of OECV will depend on the methodology applied, as well as the type of material used in the plant, as described in several studies that evaluated the same antibacterial activity by different natural methods and products of this species. The results obtained are important to collaborate with future research for new methodologies in the therapy of infections caused by multiresistant bacteria elucidating the modulating effects obtained with the combined use of LED lights associated with essential oils.
\end{abstract}

Keywords: Cordia Verbenacea. Antibacterial activity. Phototherapy. Natural products.

\footnotetext{
${ }^{1}$ Docente do Centro Universitário Dr. Leão Sampaio - UNILEÃO (Juazeiro do Norte - CE) e Orientador do PPBM da Universidade Regional do Cariri - URCA (Crato - CE). Rua Manoel Balbino 905. CEP: 63048-280. Cidade Universitária. Juazeiro do Norte-CE. ednardo@leaosampaio.edu.br. Cel.: (88) 99910-8876.
} 


\section{INTRODUÇÃO}

Desde a antiguidade o homem tem utilizado os produtos naturais na busca da cura e alívio de doenças, através da ingestão de folhas e ervas (VEIGAS; BOLZANI; BARREIRO, 2006). O uso de forma continua de plantas medicinais e o conhecimento empírico das comunidades sobre as mesmas, tem despertado o interesse em pesquisas farmacológicas relacionadas às plantas (BRASILEIRO, 2008).

A espécie Cordia verbenacea DC., conhecida popularmente como "erva-baleeira", é uma planta arbustiva, localizada em todo litoral brasileiro, especialmente na faixa entre os estados de Paraná, Santa Catarina e São Paulo (LADEIRA, 2002). Utilizada tradicionalmente pela população para tratar vários processos inflamatórios e bastante indicada para tratamento de reumatismo, artrite e problemas de coluna (LAMEIRA et al., 2009). Em estudos já foram comprovados a sua atividade antimicrobiana, anti-úlcera, anti-inflamatória e cicatrizante (CARVALHO JR et al., 2004; PASSOS et al., 2007).

Segundo Fucci et al. (2013) Escherichia coli é uma bactéria Gram negativa que habita a microbiota humana, porém pode tornar-se patogênica provocando gastroenterites, sepse e infecções do trato urinário. Staphylococcus aureus é um microrganismo que pertence à microbiota humana, trata-se de uma bactéria Grampositiva, no entanto, quando está fora da flora normal, desenvolve processos infecciosos simples até infecções graves (TIZOTTI et al., 2011).

Contudo, as doenças infecciosas são tratadas com antimicrobianos, que podem ser das classes de antibióticos como as penicilinas, beta-lactâmicos, aminoglicosídeos e as fluoroquinolonas (CORREIA, 2014). Porém, o uso indiscriminado de medicamentos permite que as bactérias sejam expostas aos mesmos e adquiram seletividade. Esta oportunidade facilita a aquisição de mecanismos de resistência (SANTOS, 2004).

Devido à dificuldade no tratamento de bactérias multirresistentes, é notória a necessidade de encontrar novas substâncias que tenham ações antimicrobianas para serem utilizadas no combate a esses microrganismos. A terapia fotodinâmica surge como uma nova alternativa neste cenário (PEREIRA et al., 2004; WILSON; MIA, 1993).

O Light Emithing Diodes (LED) vem sendo um recurso bastante promissor, ainda que pouco frequente na prática clínica, todavia já se mostra muito eficaz na atuação antibacteriana (MEYER, et al., 2010). O mesmo é caracterizado por produzir uma potência de irradiação absolutamente segura, consome pouca energia, vida útil extremamente longa, boa potência e baixa intensidade (MOREIRA, 2009).

Considerando que Cordia verbenacea é utilizada popularmente para tratamentos de doenças, se torna importantes pesquisas e experimentos com esta planta associada às luzes de LED para verificar possíveis potenciais antibacterianos. E desta forma, surgir uma nova alternativa e tratamento para o combate as bactérias multirresistentes onde seria possível observar a melhora dos pacientes com o auxílio de produtos naturais associado ao equipamento fototerápico. Portanto, o presente estudo surge com a necessidade de avaliar a atividade antibacteriana e moduladora do óleo essencial das folhas de Cordia verbenacea associada às luzes de LED.

\section{METODOLOGIA}

Coleta e identificação do material vegetal

As folhas de Cordia verbenacea foram coletadas na Chapada do Araripe, no município do Crato, Ceará, Brasil. O material vegetal foi identificado e uma exsicata da espécie foi depositada no Herbário Prisco Bezerra da Universidade Federal do Ceará sob nº 044171.

Extração do óleo essencial das folhas de Cordia verbenacea

A extração do óleo essencial das folhas frescas de Cordia verbenacea foi realizada pelo método de hidrodestilação utilizando o aparelho tipo Clevenger, onde as folhas foram trituradas e colocadas em um balão de vidro de 5,0 L juntamente com de $2,5 \mathrm{~L}$ de água destilada, permanecendo em ebulição por 2 horas. Foi adicionado sulfato de sódio anidro $\left(\mathrm{Na}_{2} \mathrm{SO}_{4}\right)$ ao óleo essencial obtido e este foi armazenado sob refrigeração ($4^{\circ}$ C) para conservação até a realização das análises (MATOS et al., 1999).

\section{Meios de Cultura}

O meio de cultura Brain Heart Infusion BHI (concentração indicada pelo fabricante e 10\%) foi adquirido de HIMEDIA, India. O meio de cultura foi preparado segundo as especificações do fabricante e esterilizado em autoclave de vapor quente.

\section{Aparelho de LED}

O aparelho utilizado durante o procedimento experimental foi o Light Emithing Diodes- LED, um diodo emissor de luz, da marca NEW Estética ${ }^{\circledR}$, o qual possui os espectros de luz vermelha, azul e amarela, permitindo também a combinação destas cores. As luzes utilizadas foram azul, com um comprimento de onda prédeterminado pelo aparelho, de $415 \mathrm{~nm}$, luz vermelha de $620 \mathrm{~nm}$ e luz amarela de $590 \mathrm{~nm}$.

\section{Linhagens bacteriana}

Foram utilizadas as linhagens multirresistentes de isolados clínicos Escherichia coli 27 e Staphylococcus aureus 358. As linhagens foram mantidas em Agar infusão de coração (HIA). Para realização dos testes, as linhagens foram suspendidas em tubo de ensaio com água destilada para obter uma suspensão com turvação equivalente a 0,5 da escala de McFarlland ( 1 x $\left.10^{8} \mathrm{UFC} / \mathrm{mL}\right)$.

\section{Teste de avaliação da atividade antibacteriana e moduladora por contato gasoso.}

Para realização da semeadura dos microrganismos, foram utilizadas placas de petri contendo Brain Heart Infusion (BHI) ágar. Discos de papéis filtro semelhantes aos de antibiograma foram colocados no centro de cada placa sobre o semeio e 10 $\mu \mathrm{L}$ do óleo essencial de Cordia verbenacea foi acrescentado na tampa das placas. Para determinação dos halos de inibição, as placas foram incubadas na estufa a $37^{\circ} \mathrm{C}$ por 24 horas. Os testes foram realizados em triplicata e para determinação dos halos foi utilizada uma régua milimetrada. Para a realização da atividade moduladora por contato gasoso em placas de petri contendo BHI, foi utilizada a metodologia modificada por Inouye; Takizawa; Yamaguchi, (2001). Foram utilizados discos de antibióticos: amicacina, gentamicina, oxacilina, norfloxacina, ciprofloxacina e penicilina. As placas foram 
divididas em grupos nos quais foram invertidas $\mathrm{e}$ adicionados em suas tampas $10 \mu \mathrm{L}$ do óleo essencial de Cordia verbenacea, permitindo que a partir da volatilização ocorra a interação com os discos. Outras placas foram preparadas sem o óleo para posterior comparação entre placas somente com os antibióticos e placas com antibióticos e óleo essencial. Para determinação dos halos de inibição, as placas foram incubadas na estufa a $37^{\circ} \mathrm{C}$ por 24 horas. Os testes foram realizados em triplicata e para determinação dos halos foi utilizada uma régua milimetrada.

\section{Avaliação da atividade moduladora com exposição ao LED}

Para a realização destes testes foi utilizada a mesma metodologia referente ao teste de avaliação da atividade antibacteriana e moduladora por contato gasoso. As placas foram subdividas em quatro grupos. Onde o primeiro foi submetido à luz de LED azul, o segundo grupo submetido à luz de LED vermelha e o terceiro grupo à luz amarela durante vinte minutos cada placa. $\mathrm{O}$ quarto grupo não foi submetido às luzes de LED. As placas foram incubadas a $35 \pm 2^{\circ} \mathrm{C}$, durante $24 \mathrm{~h}$. Os testes foram realizados em triplicata e para determinação dos halos foi utilizada uma régua milimetrada.

\section{Análise estatística}

Os resultados foram expressos em média aritmética \pm desvio padrão, avaliados estatisticamente através da análise de variância (ANOVA) seguido pelo pos-test Bonferroni utilizando o software GraphPad Prism. Onde as diferenças foram consideradas significativas quando $\mathrm{p}<0,05$.

\section{RESULTADOS E DISCUSSÃO}

Para os testes de atividade antibacteriana realizados pelo método de contato gasoso do o óleo essencial de Cordia verbenacea ( $\mathrm{OECv}$ ) combinado com as luzes de LED, em nenhuma das combinações do óleo com as luzes de LED foi observado formação de halo, indicando que este tipo de combinação não possui efeito antibacteriano.

Já em estudo feito por Carvalho Jr et al. (2004) essencial das partes aéreas da espécie Cordia verbenacea frente a bactérias Gram-negativas e Gram-positivas pelo método de difusão em ágar, no qual foi obtido atividades positivas contra bactérias Gram-positivas, sendo uma delas Staphylococcus aureus.

Foi constatada também a atividade antibacteriana do extrato etanólico das folhas de Cordia verbenacea pela metodologia de microdiluição frente as cepas de Staphylococcus aureus e Escherichia coli (128 $\mu \mathrm{g} / \mathrm{mL}$ para EC27 e $256 \mu \mathrm{g} / \mathrm{mL}$ para SA-ATCC 25923) (MATIAS et al., 2010).

No estudo de Rodrigues et al. (2012) o óleo essencial apresentou atividade antibacteriana pelo método de microdiluição frente a cepa Gram-positiva $S$. aureus ATCC 12692 e frente a Gram negativa E. coli 27.

Desta forma, a atividade antibacteriana de produtos naturais depende de diversos fatores, como: composição química da planta, processamento do vegetal, condições de estocagem e tipo do microrganismo em estudo (BERTINI et al., 2005). Como também a atividade antibacteriana de Cordia verbenacea está diretamente ligada a metodologia utilizada nos testes.

Nos testes referentes a modulação da resistência bacteriana, onde foram combinados $\mathrm{OECv}$ com antibióticos e luzes de LED, observou-se sinergismo, antagonismo e indiferença.

Os gráficos 1 e 2 representam os resultados da modulação da Amicacina e Gentamicina respectivamente combinados com o $\mathrm{OECv}$ e as Luzes de LED. Nas combinações realizadas com a amicacina frente $E$. coli foi observado a diminuição do halo quando o antibiótico foi associado ao OECv e luz de LED amarela indicando antagonismo. Frente $S$. aureus houve o aumento do halo de inibição quando a amicacina foi associado com a luz de LED azul indicando sinergismo. Para a combinação com gentamicina o mesmo apresentou efeito sinérgico quando associado as luzes de LED amarela frente a $S$. aureus. As demais combinações da amicacina e gentamicina, OECv com as luzes de LED frente $E$. coli e $S$. aureus não apresentaram diferenças estatisticamente significantes.

Gráfico 1: Modulação de Amicacina combinado ao LED e OECv

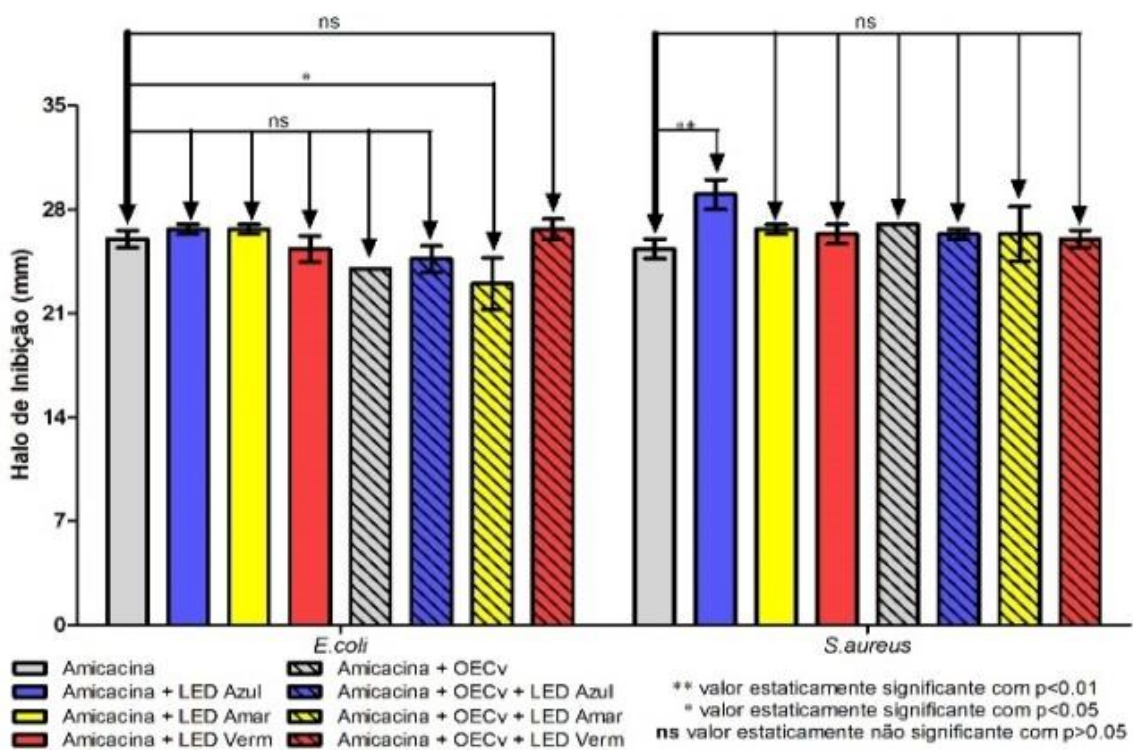


Gráfico 2: Modulação de Gentamicina combinado ao LED e OECv

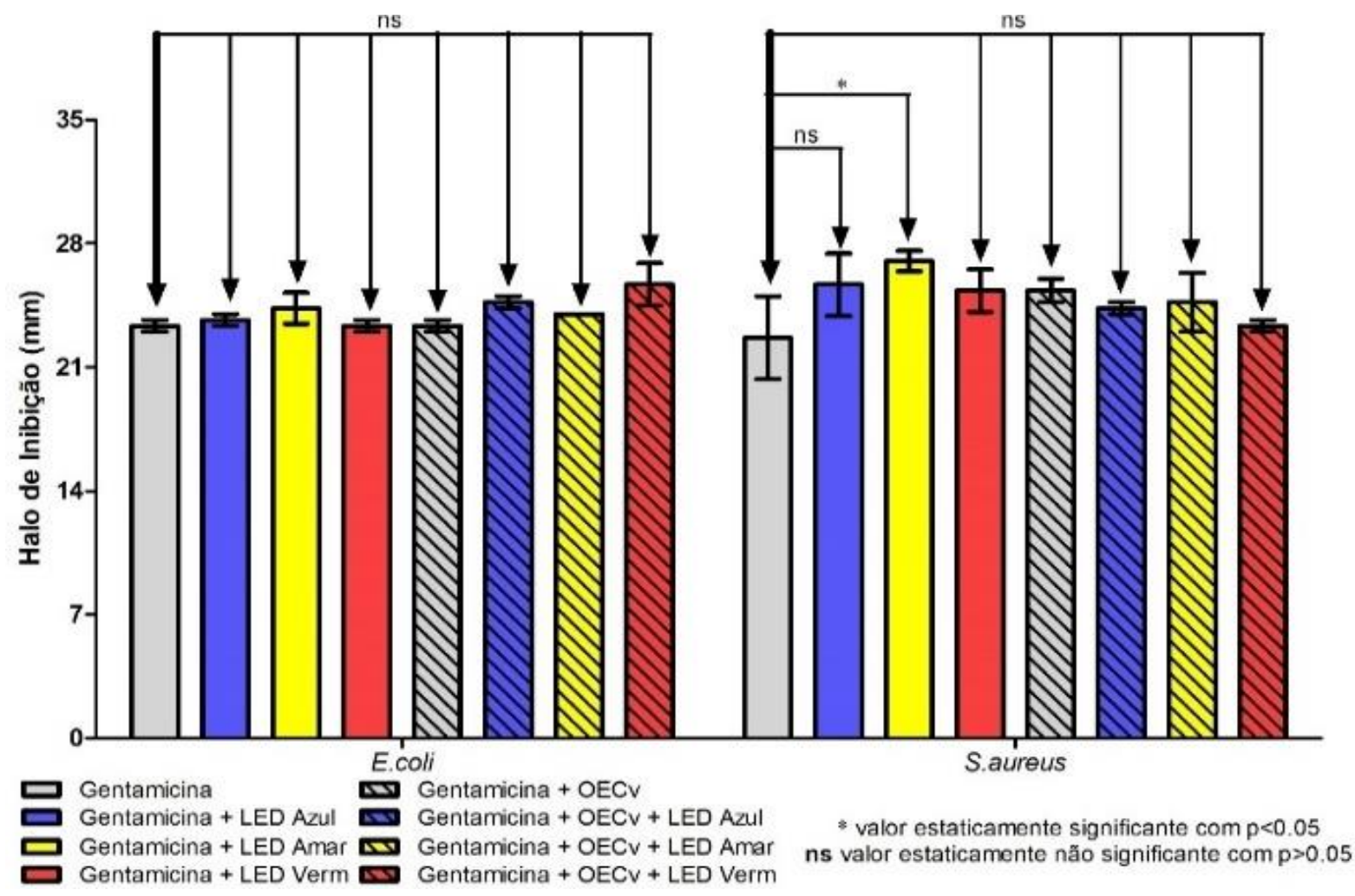

Os Gráficos 3 e 4 representam os resultados da modulação de Oxacilina e Penicilina combinado ao LED e OECv respectivamente. Nas combinações da oxacilina frente $S$. aureus apresentou o aumento do halo de inibição nas combinações do antibiótico com a luz de LED amarela e vermelha e também quando a oxacilina foi associada ao OECv e esta mesma combinação exposta as luzes de LED azul e vermelha indicando um efeito sinérgico. Para as combinações de penicilina, houve sinergismo para todas as associações do antibiótico junto à $\mathrm{OECv}$ e luz de LED azul, amarela e vermelha aumentando o halo de inibição tanto frente as cepas multirresistentes de E. coli, quanto de $S$. aureus, indicando efeito sinérgico. As demais combinações de oxacilina e penicilina, $\mathrm{OECv}$ com as luzes de LED frente E. coli e $S$. aureus não apresentaram diferenças estatisticamente

Gráfico 3: Modulação de Oxacilina combinado ao LED e OECv

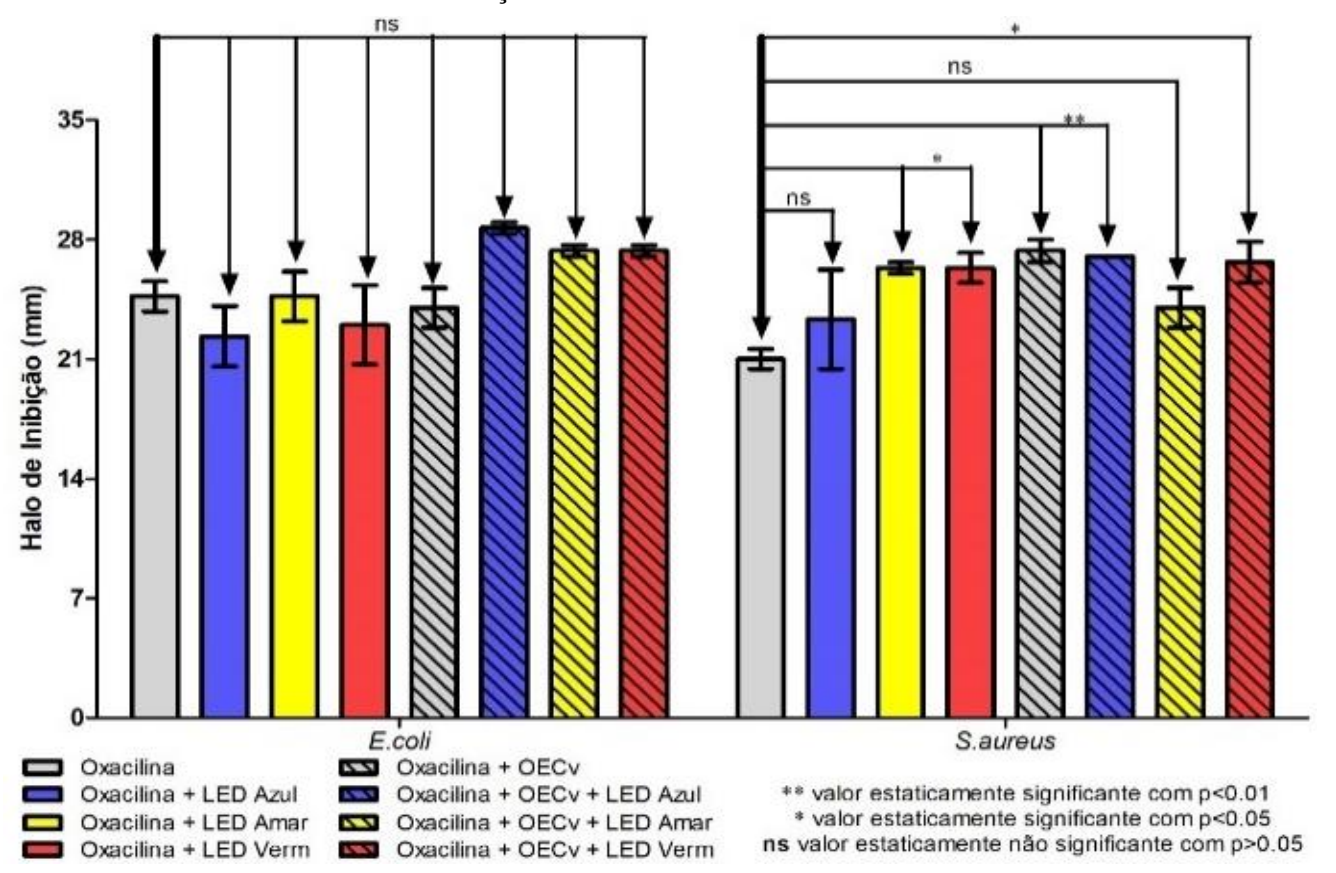




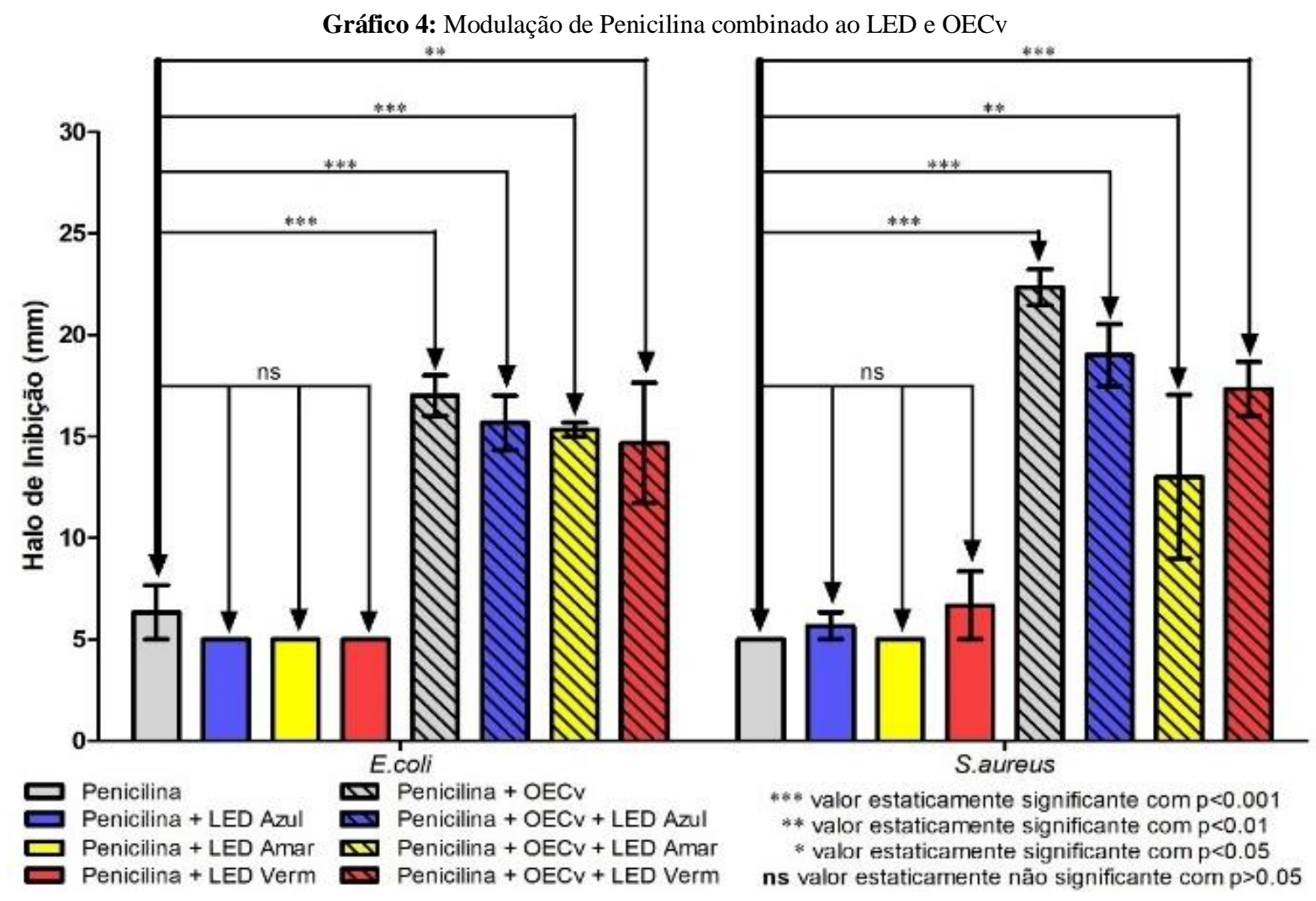

Os Gráficos 5 e 6 representam os resultados da modulação de Norfloxacina e Ciprofloxacina combinado ao LED e $\mathrm{OECv}$ respectivamente. Para a modulação com norfloxacina, todas as combinações apresentaram sinergismo frente a $S$. aureus e E. coli, exceto quando o antibiótico foi exposto a luz de LED amarela, este mesmo resultado foi observado para a modulação com ciprofloxacina frente a $E$. coli, frente a $S$. aureus houve aumento do halo de inibição quando ciprofloxacina foi exposto a luz de LED azul e vermelha, apresentando um efeito sinérgico. As demais combinações de norfloxacina e ciprofloxacina, $\mathrm{OECv}$ com as luzes de LED frente $E$. coli e $S$. aureus não apresentaram diferenças estatisticamente significantes.

Gráfico 5: Modulação de Norfloxacina combinado ao LED e OECv

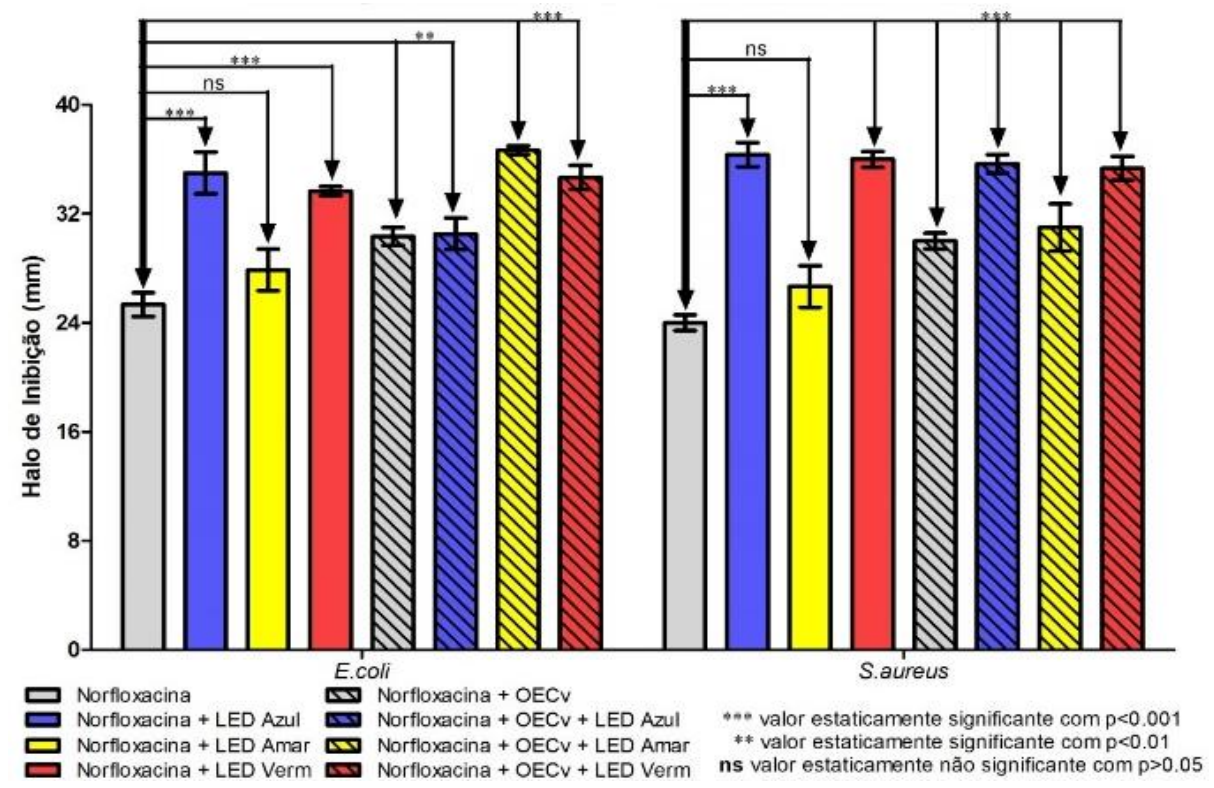


Gráfico 6: Modulação de Ciprofloxacina combinado ao LED e OECv

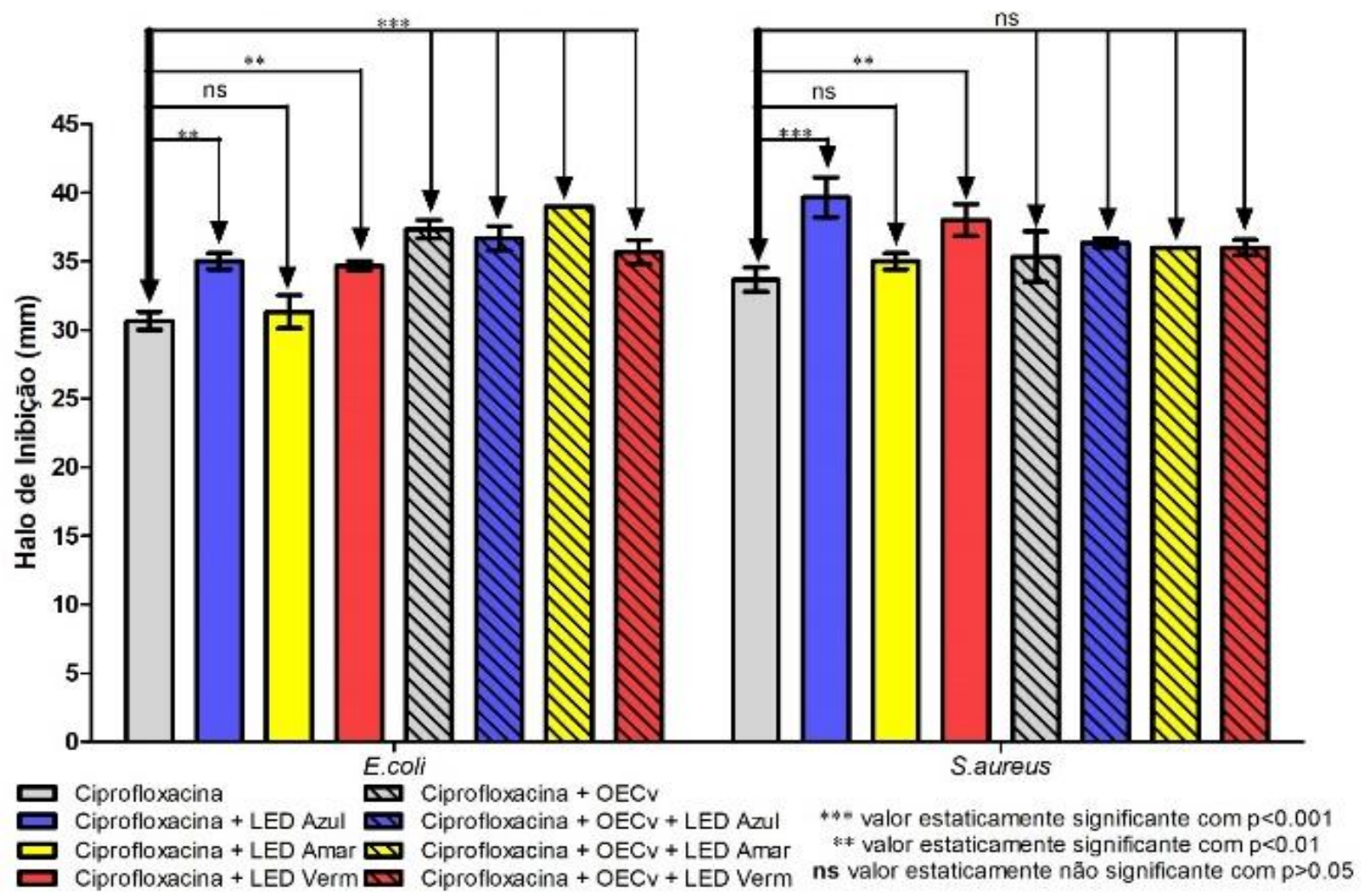

Diversos estudos vêm sendo realizados com produtos naturais em busca de novos tratamentos a infecções bacterianas. Um grande número de plantas é testado não apenas por sua atividade antimicrobiana direta, mas também como um agente modificador de resistência (GIBBONS, 2004).

Combinações de drogas e associações de antibióticos com produtos naturais de origem vegetal estão sendo aplicadas no combate à disseminação de bactérias patogênicas resistentes aos aminoglicosídeos. Essas combinações altera o efeito do antibiótico, seja revertendo à resistência ou potencializando sua atividade (COUTINHO et al., 2008).

$\mathrm{O}$ uso de óleos essenciais de plantas como agentes antimicrobianos possibilita uma baixa resistência antimicrobiana por serem misturas complexas tornando muito difícil a adaptação microbiana (DAFERERA; ZIOGAS; POLISSIOU, 2003).

Segundo Rodrigues et al. (2012), o OECv pode ser utilizado como auxiliar no tratamento antibiótico contra patógenos bacterianos do trato respiratório como também influência positivamente a atividade de antibióticos. No seu estudo foi observado a ação do $\mathrm{OECv}$ na atividade modulatória no qual o óleo foi associado aos aminoglicosídeos verificando efeito sinérgico. O presente estudo também demonstrou que o OECv melhorou a atividade de alguns antibióticos indicando efeito sinérgico, tendo atividade mais expressiva com o antibiótico Penicilina para as cepas testadas.

Em outro estudo utilizando o método do contato gasoso, foi avaliada a modificação da atividade de aminoglicosídeos, quando combinados com o óleo essencial de Lantana montevidensis no qual, também indicou bons resultados para linhagens multirresistentes (SOUSA et al., 2011).
Grebenova et al. (2003), relata que na terapia com fototerapia, o efeito pode acontecer devido alterações bioquímicas na membrana celular, inibindo a respiração celular, quando afeta a mitocôndria; causando a dissolução da célula; impede o processo de divisão celular; ainda pode inativar enzimas responsáveis pelo aumento da permeabilidade celular e pelo metabolismo celular.

A inativação fotodinâmica e a fototerapia através do uso do aparelho de LED para o controle de atividade antibacteriana, são alvos de estudo de diversos pesquisadores (GAD et al., 2004). Estudo realizado frente as bactérias $S$. aureus e $E$. coli, a fim de descobrir o comprimento de onda visível e mais efetivo para induzir a ação bactericida, demostrou que a luz de $415 \mathrm{~nm}$ pode ser utilizada na erradicação de bactérias. Porém, deve-se observar que a baixa intensidade de luz visível pode ser perigosa para promover a proliferação celular (LIPOVSKY et al., 2010).

É visto na literatura que a cor azul emitida pelo LED possui ação bactericida, através de um mecanismo denominado stress oxidativo, a luz em estudos realizados foi capaz de produzir a inativação da bactéria Propionibacterium acnes (MOREIRA, 2009). Isto pode explicar a modulação com a luz azul verificando efeito sinérgico que ocorreu entre Amicacina, Gentamicina e Oxacilina frente $S$. aureus e para Ciprofloxacina e Norfloxacina frente E. coli e $S$. aureus. Estes resultados coincidiram com o estudo feito por Pereira et al. (2017), que apresentou modulação sinérgica da luz azul quando associada a antibióticos em todos os testes promovendo a foto-inativação de bactérias Gram-positivas e Gramnegativas.

Paschoal e Ismael (2010) relata que a luz vermelha de LED possui a capacidade de penetração mais profunda nos tecidos e que possui características anti- 
inflamatórias que influenciam a liberação de citosinas dos macrófagos e outras células. No presente estudo foi possível observar a capacidade do LED vermelho aumentar o halo de inibição obtendo efeito sinérgico, este efeito pode estar associado a capacidade do LED de penetração profunda no qual ajudou o antibiótico agir dentro da célula bacteriana.

No estudo de Pereira et al. (2017) os testes de modulação por contato gasoso associado com o óleo essencial de Eugenia jambolana Lamark e luzes de LED mostraram melhores resultados quando utilizou somente o antibiótico ciprofloxacino e luzes de LED azuis e vermelhas contra as bactérias testadas. Este resultado também foi obtido no presente estudo na modulação com Oso mesmo antibiótico (Ciprofloxacino) frente $S$. aureus.

Os resultados com valores estatisticamente não significantes podem ser justificados pela estrutura da bactéria Gram-negativa na qual possui uma membrana externa que forma um envelope, desta forma, se torna dificil a ação de produtos naturais e outros medicamentos antimicrobianos (HOLLEY; PATEL, 2005). Entretanto, foi possível observar resultados relevantes frente $E$. coli na modulação com Ciprofloxacina e Norfloxacina que apresentou aumento do halo de inibição indicando efeito sinérgico. Dessa forma, o presente estudo mostra que a metodologia empregada pode modificar a resistência das bactérias Gram-negativas.

\section{CONCLUSÃO}

Os resultados obtidos nesse estudo demostraram que o óleo essencial de Cordia verbenacea associado às luzes de LED não possui efeito antibacteriano pelo método de contato gasoso, porém, quando associados a antibióticos e luzes de LED possuiu efeito modulador da resistência bacteriana. Portanto, essas descobertas se tornam importantes no intuito de colaborar com pesquisas futuras para novas metodologias na terapia de infecções com bactérias multirresistentes, visando obter efeitos moduladores com o uso das luzes de LED e óleos essenciais de plantas.

\section{REFERÊNCIAS}

BERTINI, L.M. et al. Perfil de sensibilidade de bactérias frente a óleos essenciais de algumas plantas do nordeste do Brasil. Revista Infarma, v.17, n.314, p.80-3, 2005.

BRASILEIRO, B. G. et al. Plantas medicinais utilizadas pela população atendida no "Programa de Saúde da Família", Governador Valadares, MG, Brasil. Revista Brasileira de Ciências Farmacêuticas, v. 44, n. 4, p. 630-636, 2008.

CARVALHO-JUNIOR, P. M. et al. Chemical composition and antimicrobial activity of the essential oil of Cordia verbenacea DC. Journal of ethnopharmacology, v. 95, n. 2, p. 297-301, 2004.

CORREIA, L.Modulação do estado redox em bactérias por quinoxalinas. 2014. Dissertação (Mestrado em Bioquimica em saúde) - Instituto Politécnico do Porto, Escola Superior de Tecnologia da Saúde do Porto, Porto, 2014.
COUTINHO, H. D. M. et al. A atividade antiestafilocócica in vitro de Hyptis martiusii Benth contra estirpes de Staphylococcus aureus resistentes à meticilina MRSA. Revista Brasileira de Farmacognosia, v. 18, n. 1, p. 670-75, 2008.

DAFERERA, D. J.; ZIOGAS, B. N.; POLISSIOU, M. G. The effectiveness of plant essential oils on the growth of Botrytis cinerea, Fusarium sp. and Clavibacter michiganensis subsp. michiganensis. Crop protection, v. 22, n. 1, p. 39-44, 2003.

FUCCI, A. P. B., et al. Avaliação da qualidade do processo de desinfecção em superfícies inanimadas de unidades básicas de saúde por pesquisa de biomarcadores. Revista Uniara, v.16, n.1. p. 183-190, 2013.

GAD, F. et al. Effects of Growth Phase and Extracellular Slime on Photodynamic Inactivation of Gram-Positive Pathogenic Bacteria. Antimicrobial Agents and Chemotherapy, v. 48, n. 6, p. 2173-2178, 2004.

GIBBONS, S. Anti-staphylococcal plant natural products. Natural product reports, v. 21, n. 2, p. 263-277, 2004.

GREBENOVA, D. et al. Mitocondrial and endoplasmic reticulum stress- induced apoptotic pathways are activated by 5 -aminolevulinic acid-based photodynamic therapy in HL60 leukemia cells. J Photochem Photobiol B: Biology, v. 69, p. 71-85, 2003.

HOLLEY, R.A.; PATEL, D. Improvement in shelf-life and safety of perishable foods by plant essential oils and smoke antimicrobials. Food and Nutrition Sciences. v. 22, n. 4, p. 273-292, 2005.

INOUYE, S.; TAKIZAWA, T.; YAMAGUCHI, $\mathrm{H}$. Antibacterial activity of essential oils and their major constituents against respiratory tract pathogens by gaseous contact. Journal of antimicrobial chemotherapy, v. 47, n. 5, p. 565-573, 2001.

LADEIRA, R.S. Preparação do extrato seco de Cordia verbenacea. Monografia (Especialização). Porto Alegre, 2002. Instituto Brasileiro de Estudos Homeopáticos, Faculdade de Ciências da Saúde de São Paulo, Porto Alegre. 2002.

LAMEIRA, O. A. et al. Estabelecimento de cultura de células em suspensão e identificação de flavonóides em Cordia verbenacea DC. Revista Brasileira de Plantas Medicinais, v. 11, n. 1, p. 7-11, 2009.

LIPOVSKY, A. et al. Visible light-induced killing of bacteria as a function of wavelength: implication for wound healing. Laser in Surgery and Medicine, v.42, p.467-472, 2010.

MATIAS, E. F. F. et al. Atividade antibacteriana In vitro de Croton campestris A., Ocimum gratissimum L. e Cordia verbenacea DC. Revista Brasileira de Biociências, v. 8, n. 3, p. 294-298, 2010.

MATOS, F. J. D. A. et al. Essential oil of Mentha $x$ villosa Huds. from Northeastern Brazil. Journal of Essential Oil Research, v. 11, n. 1, p. 41-44, 1999. 
MEYER, P. F. et al. Avaliação dos efeitos do LED na cicatrização de feridas cutâneas em ratos Wistar. Fisioterapia Brasil, v.11, n. 6. p. 428-432, 2010.

MOREIRA, M.C. Utilização de conversores eletrônicos que alimentam LEDs de alto brilho na aplicação em tecido humano e sua interação terapêutica. 2009. Tese (Doutorado em Engenharia Elétrica) - Universidade Federal de Santa Maria, Santa Maria, 2009.

PASCHOAL, F. M.; ISMAEL, A. P. P. B. A ação da luz no tratamento da acne vulgar. Surg Cosmet Dermatol, v. 2, n. 2, p. 117-23. 2010.

PASSOS, G. F. et al. Anti-inflammatory and anti-allergic properties of the essential oil and active compounds from Cordia verbenacea. Journal of Ethnopharmacology, v. 110, n. 2, p. 323-333, 2007.

PEREIRA, R. S., et al. Atividade antibacteriana de óleos essenciais em cepas isoladas de infecção urinária. Revista de Saúde Pública, v. 38, n. 2, p. 326-328, 2004.

PEREIRA. N. L.F., et al. Antibacterial activity and antibiotic modulating potential of the essential oil obtained from Eugenia jambolana in association with led lights. Journal of Photochemistry \& Photobiology, v. 174, n. 1, p. 144-149, 2017.

RODRIGUES, F. F.G. et al. Composição Química, Atividades Antibacterianas e Antifúngicas de Óleo Essencial de Cordia verbenacea DC Folhas. Pharmacognosy Research, v. 4. n. 3, p. 161-165, 2012.

SANTOS, N. Q. A resistência bacteriana no contexto da infecção hospitalar. Texto Contexto Enfermagem, v. 13, n. Esp., p. 64-70, 2004.

SOUSA, E. O. et al. Chemical composition and aminoglycosides synergistic effect of

Lantana montevidensis Briq.(Verbenaceae) essential oil. Records of Natural Products, v. 5, p. 60-64, 2011.

TIZOTTI, M. K. et al. Prevalência e perfil de sensibilidade de Staphylococcus aureus isolados em um hospital escola na cidade de Santa Maria, Brasil. Saúde (Santa Maria), v. 36, n. 1, p. 47-56, 2011.

VIEGAS JR, C.; BOLZANI, V. S.; BARREIRO, E. J. Os produtos naturais e a química medicinal moderna. Química Nova, v. 29, n. 2, p. 326-337, 2006.

WILSON, M.; MIA, N. Sensitisation of Candida albicans to killing by low-power laser light. Journal of oral pathology \& medicine, v. 22 , n. 8 , p. 354-357, 1993. 